\title{
Assessing Violence and Injury Surveillance in the Caribbean
}

\author{
GM Andall-Brereton ${ }^{1}$, WA Mueller ${ }^{2}$
}

\begin{abstract}
Objective: To determine the status of existing violence and injury prevention (VIP) efforts and surveillance systems in the Caribbean.

Methods: The Caribbean Public Health Agency (CARPHA) undertook a survey to gather evidence of VIP in 24 CARPHA member states. The survey was administered to national epidemiologists and non-communicable disease focal points in October 2015 using an online tool, 'Survey Monkey'. Questions were asked about the availability in each country of VIP representative surveys, policies, action plans, laws, victim support services, and surveillance systems.

Results: Nineteen (79\%) countries completed the VIP survey. Only three (16\%) countries indicated having conducted a nationally representative survey. Twelve (63\%) had not developed a national policy, and 14 (74\%) had not implemented an action plan on VIP. Each country reported the existence of VIP laws and offered victim support services, though average law enforcement ranged from $40 \%$ to $79 \%$. Nine (47\%) countries indicated using an injury registry, and 15 (79\%) reported collecting injury data using in-patient records, mainly from public hospitals. All 19 countries confirmed that records of reported violent incidents were maintained by the police. Unique identifiers were generally lacking in registries and data collected by the police. Only four (44\%) countries with registries, 10 (67\%) countries with in-patient injury data, and 12 (63\%) countries with police records indicated that the data were shared with other organizations.

Conclusion: Each country reported some level of injury surveillance system. However, such systems should be harmonized to produce more complete baseline data. The use of unique identifiers is required to reduce duplication and effectively link surveillance systems available in countries.
\end{abstract}

Keywords: Caribbean, registry, surveillance, violence and injury prevention

\section{Evaluación de la vigilancia de la violencia y las lesiones en el Caribe}

GM Andall-Brereton ${ }^{1}$, WA Mueller ${ }^{2}$

\begin{abstract}
RESUMEN
Objetivo: Determinar el estado de los sistema de vigilancia y los esfuerzos para la prevención de la violencia y las lesiones (VIP, en inglés) en el Caribe.

Métodos: La Agencia de Salud Pública del Caribe (CARPHA, en inglés) realizó una encuesta para reunir evidencias de VIP en 24 Estados Miembros de CARPHA. La encuesta fue
\end{abstract}

From: ${ }^{1}$ The Caribbean Public Health Agency, Port of Spain, Trinidad and Tobago, West Indies and ${ }^{2}$ Department of Epidemiology and Biostatistics, Imperial College London, London, United Kingdom.
Correspondence: Dr GM Andall-Brereton, The Caribbean Public Health Agency, 16-18 Jamaica Boulevard, Federation Park, Port of Spain, Trinidad and Tobago, West Indies. Email: andallgl@carpha.org 
administrada a los epidemiólogos nacionales y a los coordinadores (focal points) de enfermedades no transmisibles, en octubre de 2015 utilizando la herramienta en línea 'Survey Monkey'. Se hicieron preguntas acerca de la disponibilidad en cada país de encuestas representativas de VIP, políticas, planes de acción, leyes, servicios de apoyo a las víctimas, y sistemas de vigilancia.

Resultados: Diecinueve (79\%) países completaron la encuesta sobre VIP. Sólo tres (16\%) paises indicaron haber realizado una encuesta representativa a nivel nacional. Doce (63\%) no habian desarrollado una politica nacional, y 14 (74\%) no habían implementado un plan de acción sobre VIP. Cada país informó de la existencia de leyes para VIP y ofreció servicios de apoyo a las víctimas, aunque el cumplimiento promedio de la ley osciló entre 40\% y 79\%. Nueve (47\%) países indicaron el uso de un registro de lesiones, y 15 (79\%) informaron que recogían los datos de lesiones utilizando las historias clínicas de pacientes hospitalizados, principalmente de hospitales públicos. Los 19 países en su totalidad confirmaron que los registros de incidentes violentos reportados, fueron retenidos por la policía. Los identificadores únicos generalmente carecian de registros y datos recopilados por la policía. Sólo cuatro (44\%) paises con registros, 10 (67\%) paises con datos de lesiones en pacientes, y 12 (63\%) paises con registros policiales, indicaron que los datos se compartían con otras organizaciones.

Conclusión: Cada país reportó un cierto nivel de sistema de vigilancia de lesiones. Sin embargo, estos sistemas deben armonizarse para producir datos de referencia más completos. Se requiere el uso de identificadores únicos para reducir la duplicación y vincular eficazmente los sistemas de vigilancia disponibles en los países.

Palabras clave: Caribe, registro, vigilancia, prevención de la violencia y las lesiones

West Indian Med J 2018; 67 (4): 329

\section{INTRODUCTION}

Violence and injury have traditionally fallen outside the purview of public health; yet they are responsible for over five million deaths annually (1). Injuries disproportionately affect younger cohorts, with violence accounting for nearly $60 \%$ of male deaths in the Caribbean between the ages of five and 44 years (2). With young individuals bearing most of the injury burden, it was estimated that the potential years of life lost (PYLL) to injuries and violence surpassed the PYLL to cancer and cardiovascular disease (3).

Unintentional injuries account for the majority of all injury deaths (4), with road traffic injuries representing the highest burden. Road traffic injuries were estimated to cause 1.24 million deaths annually and were the leading global cause of death for young adults aged 15-29 years (5). The World Health Organization (WHO) estimated that over 800000 suicides occurred each year, constituting the second leading cause of death for persons aged 15-29 years; the Caribbean includes countries with two of the top five highest suicide rates in the world (6). Globally, there were estimated to be about 500000 homicides annually, with rates having declined by $16 \%$ over the period 2002-12 (7). While global rates have decreased, the Caribbean region is one of the geographical areas to experience increases in the homicide rate in recent years (8). Surveys of exposure to interpersonal violence in Caribbean nations identified rates as high as $73 \%$ in males and $83 \%$ in females, surpassing worldwide results (9).

Figure 1 presents the increasing proportionate burden of injuries to deaths in the Caribbean (10).

It was estimated that as much as $90 \%$ of injuries were preventable, emphasizing the importance of appropriate interventions (3). To support countries with capturing good, reliable data to target preventions, the Centers for Disease Control and Prevention and WHO jointly produced guidelines for establishing injury surveillance systems (11). Some Caribbean nations have already initiated such systems, but reports in the literature are limited (12). A recent systematic review examined the uptake of these guidelines. The review revealed some encouraging, but limited, efforts to establish surveillance systems; however, no Caribbean countries were included in these studies (13). 


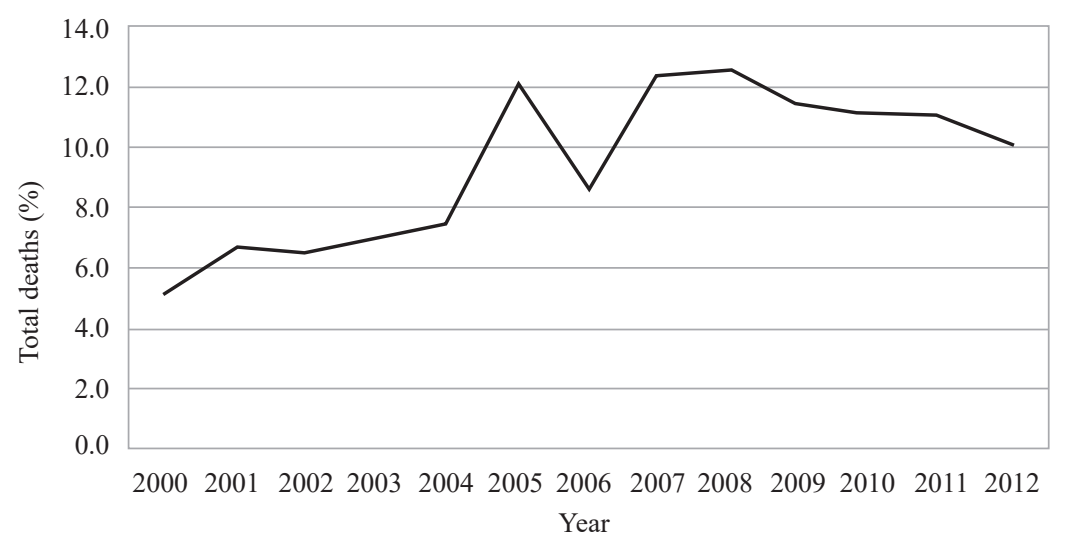

Fig. 1: Deaths due to injuries as a percentage of total deaths, 2000-12, member states of The Caribbean Public Health Agency.

Data presented do not include submissions for the following years and countries: 2000, Dominica; 2005, British Virgin Islands, Cayman Islands; 2007, British Virgin Islands; 2008, Curacao; 2009, Curacao, Jamaica; 2010, Antigua and Barbuda, Curacao, Jamaica, Trinidad and Tobago, Turks and Caicos Islands; 2011, Antigua and Barbuda, Bermuda, British Virgin Islands, Cayman Islands, Curacao, Jamaica, Suriname, Trinidad and Tobago, Turks and Caicos Islands; 2012, Bahamas, Barbados, Bermuda, British Virgin Islands, Cayman Islands, Curacao, Guyana, Jamaica, Trinidad and Tobago, Turks and Caicos Islands (Appendix).

Surveillance systems are important for quantifying the problem of injuries and violence in each respective country and in the region. Such systems are also useful for monitoring and evaluating the impact of interventions implemented for violence and injury prevention (VIP). As a means of gathering information to guide the improvement of systems for surveillance of violence, The Caribbean Public Health Agency (CARPHA) conducted a study with the following objectives:

- to determine the status of existing VIP efforts;

- to assess the extent to which violence and injury data were collected; and

- to produce recommendations to improve violence and injury surveillance.

\section{SUBJECTS AND METHODS}

A questionnaire on VIP activities was designed using information gleaned from the literature and disseminated to CARPHA member states (Appendix). In general, the survey inquired about the availability of the following features of VIP frameworks and routine data collection:

- nationally representative survey on violence and injury;

- national VIP policy;

- national VIP action plan;

- VIP laws and the extent of enforcement;

- $\quad$ support services for victims of violence;

- $\quad$ violence and injury registry;

- hospital database of in-patient injuries; and

- police records of violent incidents.
A final, open-ended question was added to the survey, which asked respondents to provide any suggestions to improve violence and injury surveillance.

The survey questions developed on the aforementioned topics were compiled and administered using the online software, 'Survey Monkey'. The content was reviewed by CARPHA's bioethicist to ensure that potential respondents were provided with all pertinent information regarding survey submission and that there were no violations of ethical principles. An online link to the survey was emailed to both the Non-communicable Disease Focal Point and National Epidemiologist in each country in October 2015.

\section{RESULTS}

Nineteen of the 24 CARPHA member states (79\%) completed the VIP survey. The majority (17/19) of the respondents were representatives from Ministries of Health. Haiti and Trinidad and Tobago, with the first and third largest population sizes in the region, respectively, were among the five countries which did not respond to the survey.

\section{Framework of violence and injury prevention}

Only three of the 19 countries (16\%) reported having undertaken a nationally representative survey on violence and injury. Just over a third $(37 \% ; 7 / 19)$ of the countries confirmed implementing a national VIP policy, and slightly over a quarter $(26 \% ; 5 / 19)$ of the countries reported having a VIP action plan. All seven national 
VIP policies, and most of the VIP action plans, targeted child maltreatment, intimate partner violence, and sexual violence, while one action plan focussed solely on road safety.

Respondents were asked about categories of VIP laws implemented in their countries, including abuse of the elderly, alcohol use/abuse, intimate partner violence, youth violence, child maltreatment, and sexual violence. Slightly over half $(53 \% ; 10 / 19)$ of all countries described implementing each of these categories of VIP laws. Laws pertaining to abuse of the elderly were the least implemented $(53 \% ; 10 / 19)$, while sexual violence laws were most common and were implemented in every country.

In regard to law enforcement, sexual violence laws, implemented in each country, were among the least enforced, while abuse of the elderly, though least likely to be implemented, was in fact the most enforced by the countries. Nevertheless, there was little variation overall in average enforcement levels among the different categories of laws. On average, laws were reportedly enforced $40-79 \%$ of the time in the countries (Fig. 2).

Countries were also asked about the availability of support services to assist victims of violence and injury, namely, halfway houses, clinics, hotlines and shelters. With the exception of halfway houses, at least half of the countries reported offering each of these violence and injury support services, with shelters being the most common.

\section{Systems for surveillance of injuries and violence}

The online questionnaire highlighted three main areas of routine collection of injury data: injury registries, in-patient records from hospitals, and police files on violent incidents. Less than half $(47 \%$; 9/19) of the countries reported using an injury registry, while just over three quarters $(79 \% ; 15 / 19)$ of the countries indicated recording injury data from in-patients at public and/ or private hospitals. All countries stated that the police force collected data regarding violent incidents. Eight $(42 \% ; 8 / 19)$ of the countries confirmed using all three data systems to collect and compile injury data: a registry, in-patient records and police files.

The survey asked for the collection of 17 variables used for routine injury surveillance. All countries reported common elements of each injury incident in registries, in-patient records and police files. Place, gender, date and residence were the variables which were most frequently collected. However, unique identifiers were not used in almost half $(44 \% ; 4 / 9)$ of the registries and more than two-thirds $(68 \% ; 13 / 19)$ of the police records.

Of the nine countries with injury registries, more than three-quarters $(88 \% ; 8 / 9)$ reportedly reflected data originating from public hospitals, of which three also included data from community health centres. One of these registries was inclusive of data from both public and private hospitals, as well as community health centres. Another did not include data for public hospitals, but did confirm collecting data from private hospitals and community health centres.

Thirteen of the 15 countries that noted collecting inpatient injury data did so from public hospitals, including three that also obtained injuries documented at community health centres and two others from private hospitals. Four countries confirmed collecting such data from both

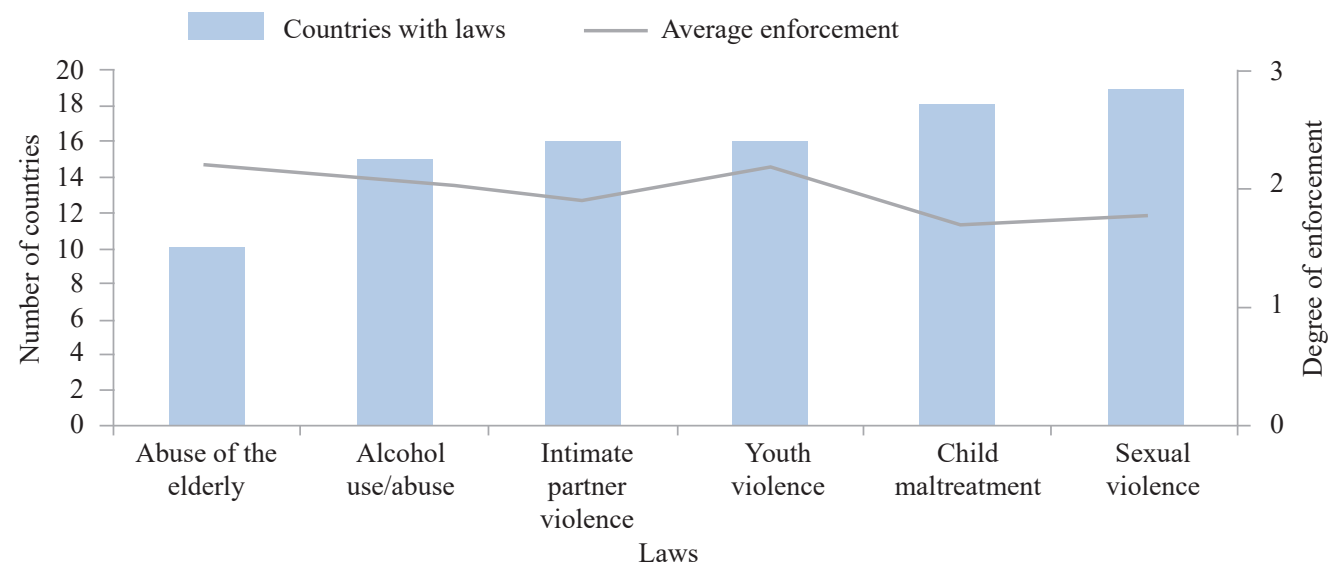

Fig. 2: Implementation and average enforcement of laws of violence and injury prevention by category, as adopted by the World Health Organization (7). 1 = limited enforcement $(<40 \%), 2$ = enforced to a large extent $(40-79 \%)$ and 3 = fully enforced $(>80 \%)$. 
public and private hospitals, in addition to community health centres, and one country stated that injury data were collected exclusively from private hospitals.

Almost half $(44 \% ; 4 / 9)$ of the countries with injury registries, more than half $(67 \% ; 10 / 15)$ of the countries with in-patient records, and $63 \%(12 / 19)$ of all countries with police files on violent incidents confirmed that these data were shared with other organizations. Data from four of the nine injury registries were provided to the police department. Three countries indicated sharing data with Ministries of Health and other government agencies on an ad hoc basis. In all, only two countries $(11 \% ; 2 / 19)$ confirmed that data were shared from both public and private hospitals.

\section{DISCUSSION}

While some CARPHA member states exhibited a stronger approach to VIP, as evidenced by the responses to the survey, it was also evident that there were missed opportunities to quantify the burden of violence and injuries.

\section{Framework of violence and injury prevention}

A limited number of countries had conducted nationally representative surveys, a Caribbean trend that apparently has not improved (14). Without important baseline information for developing appropriate indicators and targets in each country, it would be difficult to reduce the specific burden of violence and injuries (7). In order to establish baseline data on injuries and violence for a country, nationally representative surveys should be completed where such data are not available.

Most surveyed countries confirmed already having implemented various VIP laws, a necessary step in effective interventions for VIP (15). With respect to enforcement of VIP laws, respondents indicated that the laws were on average only partly enforced in most countries. While promising, this category still represents wide variation in enforcement, and efforts should be made to identify the gaps and determine how legal enforcement could be strengthened.

As legal mechanisms are necessary to deter potential perpetrators, a range of support services should be available for victims of violence, regardless of whether cases are reported to authorities or not $(16,17)$. A variety of support options were reported by the countries, with several offering all surveyed support services. Despite this reported availability of services, respondents did not indicate that data from these sources were being captured by injury surveillance systems. Collecting additional data from sources of available support services to incorporate into injury surveillance systems should be made a priority.

\section{Systems for surveillance of injuries and violence}

Several surveillance variables were captured by most of the existing systems. However, few police records and registries included a unique identifier for each incident, in contrast to in-patient records where unique identifiers were widely used. Identifiers are used to ensure that the injury is recorded as a unique incident and that information shared with other agencies (eg hospitals and police departments) does not lead to double counting of the same record (11). Standardizing surveillance variables within a country and the use of unique identifiers can assist with harmonizing surveillance systems and can lead to improvement in the quality of data for calculating the prevalence of violence and injuries.

The results of this survey suggest that data from both injury registries and in-patient record surveillance systems were collected more widely by public hospitals when compared with private facilities. If the nature of injuries treated at private hospitals differs from that seen at public hospitals, the classification of the former injury would be missed, and biases in reported national injury data could result. Evidence suggests that the proportion of injuries treated at private facilities was not insignificant (18). Less-than-complete injury coverage limits a country's ability to quantify accurately the prevalence of intentional and unintentional injuries. Where possible, data should be harmonized in existing surveillance systems in respective countries.

Each country confirmed that the police force collected injury data on violent incidents. Though it is somewhat reassuring that the police force is monitoring intentional injuries, unintentional (non-violent) injuries may be missed in such a system. Since unintentional injuries constitute a larger burden of all injuries, tracking such events would be crucial for an injury surveillance system. Some countries identified the police as the only source of injury data collected, but this data source alone will be insufficient for effective injury surveillance. Depending on available resources, it is recommended that such jurisdictions should either work towards expanding the injury surveillance into hospitals or conduct a nationally representative survey to improve the estimation of injury prevalence in the country (1).

All countries surveyed reported having an injury surveillance system that was collecting some level of data on intentional injuries, with some also tracking unintentional injuries. Current surveillance efforts should be 
improved to better assess and identify the magnitude of violence and injury in the countries. Expanding the use of unique identifiers to harmonize surveillance systems would help to establish more accurate baseline data to provide information for defining national policies and action plans on VIP. Advancing VIP frameworks in each country can also lead to the establishment of a coordinated regional approach to develop and implement interventions geared towards reducing the burden of injuries in the Caribbean.

\section{ACKNOWLEDGEMENTS}

The authors extend their sincere thanks to the Ministries of Health of the 19 CARPHA member states that participated so willingly in this survey.

\section{AUTHORS' NOTE}

This study was conceptualized by GM Andall-Brereton, and the data collection instrument was developed by WA Mueller and reviewed by Andall-Brereton. Mueller administered the survey. The results of the survey were analysed by Mueller, who also wrote the first draft of the manuscript. Andall-Brereton edited and finalized the manuscript. Andall-Brereton is an employee of CARPHA. The authors declare no conflict of interest.

\section{REFERENCES}

1. Schopper D, Lormand JD, Waxweiler R. Developing policies to prevent injuries and violence: guidelines for policy-makers and planners. Geneva, Switzerland: World Health Organization; 2006.

2. Crawford TV, Mcgrowder DA, Barnett JD, Shaw-Sanderson JH. Epidemiological features of violence-related injuries in Jamaica. J Clin Diagn Res 2014; 8: JC01.

3. Plummer JM, Ferron-Boothe D, Meeks-Aitken N. Trauma in the developing world: the Jamaican experience. West Indian Med J 2014; 63: 267-70.

4. Chandran A, Hyder AA, Peek-Asa C. The global burden of unintentional injuries and an agenda for progress. Epidemiol Rev 2010; 32: 110-20.

5. World Health Organization (WHO). Global status report on road safety 2013. Geneva, Switzerland: WHO; 2013.

6. World Health Organization (WHO). Preventing suicide: a global imperative. Geneva, Switzerland: WHO; 2014

7. World Health Organization (WHO). Global status report on violence prevention 2014. Geneva, Switzerland: WHO; 2014.

8. United Nations Office on Drugs and Crime (UNODC). Global study on homicide. Vienna, Austria: UNODC; 2011.

9. Le Franc E, Samms-Vaughan M, Hambleton I, Fox K, Brown D. Interpersonal violence in three Caribbean countries: Barbados, Jamaica, and Trinidad and Tobago. Rev Panam Salud Publica 2008; 24: 409-21.

10. The Caribbean Public Health Agency (CARPHA). CARPHA regional mortality database. 2014; unpublished.
11. Holder Y, Peden M, Krug E, Lund J, Gururaj G, Kobusingye O. Injury surveillance guidelines. Atlanta, USA: Centers for Disease Control and Prevention and World Health Organization; 2001.

12. Ward E, McCartney T, Arscott-Mills S, Gordon N, Grant A, McDonald $\mathrm{AH}$ et al. The Jamaica injury surveillance system: a profile of the intentional and unintentional injuries in Jamaican hospitals. West Indian Med J 2010; 59: 7-13.

13. Kipsaina C, Ozanne-Smith J, Routley V. The WHO injury surveillance guidelines: a systematic review of the non-fatal guidelines' utilization, efficacy and effectiveness. Public Health 2015; 129: 1406-28.

14. United Nations Office on Drugs and Crime (UNODC). Crime, violence, and development: trends, costs, and policy options in the Caribbean: report no. 37820. UNODC and World Bank; 2007.

15. Haegerich TM, Dahlberg LL, Simon TR, Baldwin GT, Sleet DA, Greenspan AI et al. Prevention of injury and violence in the USA. Lancet 2014; 384: 64-74.

16. Henning KR, Klesges LM. Utilization of counseling and supportive services by female victims of domestic abuse. Violence Vict 2002; 17: 623-36.

17. Robinson L, Spilsbury K. Systematic review of the perceptions and experiences of accessing health services by adult victims of domestic violence. Health Soc Care Community 2008; 16: 16-30.

18. Orces $\mathrm{CH}$. Trends in hip fracture rates in Ecuador and projections for the future. Rev Panam Salud Publica 2011; 29: 27-31.

APPENDIX: LIST OF MEMBER STATES OF THE CARIBBEAN PUBLIC HEALTH AGENCY

\begin{tabular}{lc}
\hline Member state & Submitted the survey? \\
\hline Anguilla & Yes \\
Antigua and Barbuda & Yes \\
Aruba & Yes \\
The Bahamas & Yes \\
Barbados & Yes \\
Belize & Yes \\
Bermuda & Yes \\
British Virgin Islands & Yes \\
Cayman Islands & Yes \\
Dominica & Yes \\
Grenada & Yes \\
Jamaica & Yes \\
Montserrat & Yes \\
St Kitts and Nevis & Yes \\
St Lucia & Yes \\
St Maarten & Yes \\
St Vincent and the Grenadines & Yes \\
Suriname & Yes \\
Turks and Caicos Islands & Yes \\
Bonaire, Saba, St Eustatius & No \\
Curacao & No \\
Guyana & No \\
Haiti & No \\
Trinidad and Tobago & \\
\hline
\end{tabular}

